\title{
A EDUCAÇÃO EM SAÚdE REALIZADA POR PROFISSIONAIS DA SAUDE DA ESTRATÉGIA SAÚDE DA FAMÍLIA
}

\author{
Priscila da Silveira JÁCOME ${ }^{1}$ \\ Janieiry Lima de ARAÚJO² \\ Andrezza Karine Araujo de Medeiros PEREIRA ${ }^{3}$ \\ Renata Borges de VASCONCELOS ${ }^{4}$ \\ Ellany Gurgel Cosme do NASCIMENTO 5
}

\begin{abstract}
${ }^{1}$ Enfermeira. Graduada pela Universidade do Estado do Rio Grande do Norte (UERN). Tenente Ananias/RN - Brasil. E-mail: priscilarui_19@hotmail.com.

${ }^{2}$ Mestre em Cuidados Clínicos em Saúde. Área de Concentração: Enfermagem pela Universidade Estadual do Ceará (UECE). Professora do Curso de Enfermagem (CAMEAM - UERN). Líder do Grupo de Pesquisa Conhecimento, Enfermagem e Saúde das Populações (GRUPESCES/UERN). Pau dos Ferros/RN - Brasil. Email: janieiry@hotmail.com.

${ }^{3}$ Mestra em Saúde da Família (UFRN). Professora do Curso de Enfermagem (CAMEAM - UERN). Líder do Grupo de Pesquisa Conhecimento, Enfermagem e Saúde das Populações (GRUPESCES/UERN). Pau dos Ferros/RN - Brasil. Email: andrezza_kam@hotmail.com.

${ }^{4}$ Enfermeira. Graduada pela Universidade do Estado do Rio Grande do Norte (UERN). Especialista em Auditoria em Serviços de Saúde, Faculdade de Ciências sociais Aplicadas (FACISA). Membro do Grupo de Pesquisa Conhecimento, Enfermagem e Saúde das Populações (GRUPECES/UERN). E-mail: renatinhaam28@gmail.com

${ }^{5}$ Doutoranda em Ciências da Saúde (UFRN). Professora do Curso de Enfermagem (CAMEAM - UERN). Líder do Grupo de Pesquisa Conhecimento, Enfermagem e Saúde das Populações (GRUPESCES/UERN). Pau dos Ferros/RN Brasil. E-mail: ellanygurgel@ hotmail.com.
\end{abstract}

Recebido em: 14/07/2015 - Aprovado em: 12/01/2016 - Disponibilizado em: 30/07/2016

\section{RESUMO}

Estudo qualitativo, descritivo e exploratório que objetivou compreender as concepções teóricas e práticas de educação em saúde dos profissionais da Estratégia Saúde da Família do município de Tenente Ananias/RN. Foram 08 entrevistados. A interpretação das informações através da Análise de Conteúdo resultou em 06 categorias de análise. As concepções e práticas da educação em saúde estão atreladas a pedagogia tradicional. As ações educativas são meramente informativas. Reproduzem a noção moralista e autoritária das noções de prevenção. O cuidado de saúde das equipes não está comprometido com a efetivação da integralidade. A educação em saúde deve ser instrumento capaz de contribuir para a mudança do modelo de saúde assistencial e hegemônico existente. As concepções sobre Educação e Saúde precisam ser repensadas para que as práticas educativas promovam o trabalho coletivo em saúde compatível com a resolução das necessidades apresentadas pela população.

PALAVRAS CHAVE: Saúde da Família. Educação em Saúde. Cuidado Integral.

\section{HEALTH EDUCATION HELD BY HEALTH PROFESSIONALS OF FAMILY HEALTH STRATEGY}

\begin{abstract}
Qualitative study, descriptive and exploratory study aimed to understand the theoretical concepts and practical education of health professionals in the Family Health Strategy of the municipality of Lieutenant Ananias / RN. 08 were interviewed. The interpretation of the information through the content analysis resulted in 06 categories of analysis. The concepts and practices of health education are linked to traditional pedagogy. Educational activities are merely informative. Reproduce the notion moralistic and authoritarian notions of prevention. The health care teams is not committed to the realization of completeness. Health education should be an instrument to help change the health care model and existing hegemonic. Conceptions of Education and Health need to be rethought to promote educational practices in health work supports the resolution of the needs of the population.
\end{abstract}

KEYWORDS: Family Health. Health Education. Caution Integral. 


\section{EDUCACIÓN PARA LA SALUD EN PODER DE PROFESIONALES DE LA SALUD DE LA ESTRATEGIA DE SALUD DE LA FAMILIA}

\section{RESUMEN}

Estudio cualitativo, descriptivo y exploratorio, tuvo como objetivo comprender los conceptos teóricos y prácticos de la educación de profesionales de la salud en la Estrategia Salud de la Familia del municipio de Teniente Ananías / RN. 08 fueron entrevistados. La interpretación de la información a través del análisis de contenido se tradujo en 06 categorías de análisis. Los conceptos y prácticas de la educación para la salud están relacionados con la pedagogía tradicional. Las actividades educativas son meramente informativos. Reproducir la noción moral y nociones autoritarias de prevención. Los equipos de atención de salud no se compromete a la realización de la exhaustividad. Educación para la salud debe ser un instrumento para ayudar a cambiar el modelo de atención de salud y existente hegemónico. Concepciones de la Educación y de la Salud necesitan ser repensadas para promover prácticas educativas en el trabajo de la salud apoya la resolución de las necesidades de la población.

PALABRAS CLAVE: Salud de la Familia. Educación Integral en Salud.

\section{INTRODUÇÃO}

A educação em saúde se enquadra como um forte elo na construção dos ideais pretendidos pela política da promoção a saúde. Mediante esta tecnologia, busca-se gradativamente superar os desafios que se colocam a prática da saúde coletiva, de modo a modificar os atuais entraves e resistências que ainda prevalecem no contexto atual da política sanitária brasileira. (STOTZ, 2004).

A educação em saúde vislumbra práticas pedagógicas participativas, construtivas e transversais, desenvolvidas com gestores, movimentos sociais, grupos populacionais específicos e a população em geral, em sua maioria com o objetivo de sensibilizá-los para a aderência a projetos que contemplam as estratégias propostas. (CASTRO e MALO, 2006)

Ainda assim, a discussão que permeia as práticas da educação em saúde na dinâmica dos serviços atuais, especificamente, as atividades desenvolvidas no âmbito da Estratégia Saúde da Família (ESF), se encontra atrelada aos discursos higienistas e moralistas. Tal fato restringe a atuação dos profissionais de saúde junto aos usuários, que por sua vez não conseguem vislumbrar a real importância das atividades educativas em relação ao cuidado em saúde. (VASCONCELOS, 2004).

O usuário do SUS, não consegue perceber as possíveis contribuições das tecnologias educacionais para a sua saúde, ao mesmo tempo, os serviços não conseguem promover ações atrativas, interativas e dialógicas para com sua clientela, o que determina o distanciamento dos usuários dessa atividade, que se perde nos seus objetivos. (VASCONCELOS, 2004).

O que se percebe é a existência de um grande distanciamento entre as atuais práticas cotidianas de educação em saúde e a proposta do SUS, pois os indivíduos permanecem assistidos meramente no momento da cura, o que determina que estes retornem rapidamente aos serviços de saúde após a essa "cura imediatista", isso porque os hábitos de vida não são modificados, não há a 
compreensão dos determinantes desse adoecimento, e muito menos, a orientação adequada a que necessitam. (VASCONCELOS, 2004). É preciso utilizar os diversos espaços para realizar a educação em saúde e não exclusivamente através de palestras pontuais e eventuais realizadas.

Diante disso o estudo objetivou conhecer as concepções e práticas de educação em saúde desenvolvidas pelas Equipes da Saúde da Família de Tenente Ananias/RN, com vista à promoção da saúde e ao cuidado integral. Buscou-se uma aproximação entre a educação em saúde na perspectiva da promoção a saúde, considerando para isso a relevância da cultura popular e o seu encontro com o conhecimento científico para que assim seja construída a autonomia dos sujeitos para o cuidado da sua própria saúde, ou seja, a construção da cidadania dos sujeitos.

\section{METODOLOGIA}

Trata-se de um estudo descritivo, de natureza qualitativa aprovado pelo Comitê de Ética e Pesquisa (CEP/UERN) no dia 02 de Março de 2011, sob a CAAE $n^{\circ}$ 0106.0.428.000-10. A pesquisa foi realizada na cidade de Tenente Ananias/RN, localizada na mesorregião do Alto Oeste Potiguar. Apresenta uma área territorial de aproximadamente $224 \mathrm{~km}^{2}$, distando da cidade do Natal $410 \mathrm{~km}$. Dispõe de uma população total aproximada de 9.833 habitantes, sendo estes distribuídos entre zona rural e urbana (IBGE, 2010).

Na Atenção Primária à Saúde, a gestão municipal, conta com 04 (quatro) Equipes da Estratégia Saúde da Família, que atuam em áreas específicas de abrangência mista, ou seja, as atividades dividem-se entre a zona urbana e rural. Porém, o município dispõe apenas de um centro de saúde como sede para o trabalho das quatro equipes da ESF, situada no centro urbano desta cidade.

Os participantes do estudo foram os profissionais de nível superior que atuam nas equipes saúde da família. O convite para participar ocorreu por telefone. A coleta de dados foi agendada de acordo com a disponibilidade do participante e realizou-se em seu local de trabalho. Para coletar os dados, realizamos a entrevista semiestruturada aplicada com 08 profissionais da saúde, após os critérios de inclusão, sendo quatro enfermeiros, dois médicos e dois odontólogos. A gravação das entrevistas ocorreu no período de 01 de Junho a 01 de Julho de 2011.

A análise dos dados coletados se deu mediante o método da Análise de Conteúdo (AC). Dos depoimentos emergiram seis categorias analíticas que compõe os resultados/discussões desta pesquisa. 


\section{RESULTADOS}

CATEGORIA 1 - As diferentes concepções

de saúde dos profissionais da ESF: a

\section{tradicional e a ampliada.}

As concepções sobre saúde se mostram condizentes com os processos de formação de cada área de conhecimento, as quais tendem a influenciar nas ações práticas de educação em saúde.

Nas falas foram identificadas duas concepções sobre saúde: a concepção tradicional, que define a saúde como ausência de doenças, de caráter unicamente biologicista, reduzindo o indivíduo unicamente ao que a afeta momentaneamente. E a outra concepção, da saúde ampliada, esta seria resultado de determinantes sociais presentes nos grupos sociais homogêneos, o qual amplia a rede causal, para além do fator biológico, ou seja, o processo saúde-doença sofre interferência do meio social, econômico, cultural e/ou psíquico. Demonstrando assim, os limites conceituais dos interlocutores sobre o tema.

Saúde faz parte da vida da gente de um modo geral (...), acho que é tudo na vida de um ser humano.

(PROFISSIONAL

DE SAÚdE A)
Saúde, ao meu modo de ver, é o bem estar do paciente em todas as

circunstâncias.

(PROFISSIONAL DE SAÚDE B)

Saúde, em minha opinião, seria a ausência total de qualquer enfermidade.

\section{(PROFISSIONAL}

DE SAÚDE D)

A saúde envolve três categorias, é o principal para o ser humano, porque a saúde diz respeito à saúde física, mental, e psicológica, eu acho que o individuo tendo uma boa saúde ele está apto a desenvolver qualquer atividade.

(PROFISSIONAL DE SAÚDE G)

Pra mim a saúde é um bem estar físico, mental, é ver o ser 
humano como o todo, onde o cliente ele possa ter o direito não só ao cuidado com a doença, mas que ele tenha lazer uma moradia, saneamento básico onde ele mora, onde ele vive, é um conjunto de fatores que possa levar a uma boa qualidade de vida do ser humano.

\section{(PROFISSIONAL} DE SAÚDE C)

Observa-se em depoimentos o apego a concepção tradicional. A saúde reduzida a abordagem historicamente hegemônica e fundamentada no referencial biologicista e num modelo de intervenção que busca a prevenção de doenças pela mudança de atitudes e comportamentos individuais não contribuindo para a edificação de processos educativos inovadores. Os discursos geram a compreensão de uma concepção de saúde, limitada que consolida o modelo hegemônico do cuidado em saúde biomédico. (CARVALHO e CUNHA, 2006). Quando há o prevalecimento dessa noção, logo se atribui as questões de saúde e doença a culpabilização do sujeito em relação ao seu estado, não consideram desse modo os determinantes sociais que interferem no processo saúde-doença.

Portanto, visualizar a saúde de modo ampliado ainda se mostra como algo novo para os entrevistados, entretanto, tal avanço se faz necessário para a construção de um cuidado integral mais condizente com as necessidades e problemas apontados pelos usuários na realidade dos serviços de saúde da ESF, levando-nos ao pilar da saúde compreendida por meio de um processo saúde-doença que é resultante de determinantes sociais. É notório nas falas que há restrição na definição de um termo que tem um significado amplo. Isso reflete diretamente na prática de educação em saúde dos profissionais, nas atitudes e ações de cuidado dirigidas a população.

\section{CATEGORIA 2 - A Educação em saúde} perpetua as práticas preventivas pautadas em ações autoritárias e na dicotomia do saber entre o profissional e o usuário.

Apresenta as concepções dos profissionais da ESF sobre o significado do termo educação em saúde, demonstrando nos discursos o que eles pensam e o que fazem no que se refere a esta atividade.

A educação e a saúde recebem ao longo da história diferentes concepções por estar intimamente ligada ao modelo de atenção a saúde vigente e ao modelo de produção da sociedade, a compreensão da 
educação em saúde sofre essa mesma influência, estando sempre atreladas as ideologias políticas e econômicas da época. (BORDENAVE, 1999). parte preventiva com

uma simples

campanha, uma

simples palestra você pode prevenir várias doenças como a dengue, $\quad$ você esclarecer a população, como é que deve fazer para evitar a proliferação do mosquito, por exemplo, eu acho que é isso aí, a parte preventiva, a educação da população é fundamental.

\section{(PROFISSIONAL} DE SAÚDE G)
(PROFISSIONAL

DE SAÚDE G)

(...) a saúde começa logo pela parte preventiva, você deve logo partir da prevenção, porque se a população não tiver bem preparada, esclarecida sobre se cuidar eu acho que vai ter problema em relação aos outros fatores, porque só a
É evidente nas falas, o caráter preventivo pautado simplesmente no repasse de informações entre o profissional e o usuário, em que o educador é o detentor do saber e o educando participa do processo passivamente, recebendo e reproduzindo essas informações, de modo que a culpa pelo adoecimento se direciona ao indivíduo apenas.

Podemos observar na fala que se segue a unilateralidade da informação, uma vez que o profissional impõe a receita básica para se ter boa saúde e a população escuta o que tem que ser feito, não evidenciado a formação de 
opinião, e a construção crítica e reflexiva dos sujeitos envolvidos no processo de construção da educação em saúde. Vale ressaltar a perpetuação das atividades educativas voltadas para a execução de ações preventivas.

(...) a educação em saúde é muito importante, (...). A atividade educativa que a gente realiza na unidade tem uma importância porque informa, educa, nessas atividades, tira dúvidas da população, dos grupos de assistência que realiza essas atividades. A gente trabalha também nas escolas, onde leva materiais educativos de várias formas como o álbum seriado, leva material para expor em data show, e é muito bom trabalhar com orientações, cuidados da saúde para melhorar a saúde, evitar doenças, como as DSTs. Como é feita palestras sobre DSTs, a gente ver a necessidade e a importância não só desse tema, mas como outros também que a gente trabalha, levando educação, saúde, levando orientações de saúde. Esclarece, informamos muitas vezes conceitos que não são certos, eles esclarecem nessas atividades.

\section{(PROFISSIONAL} DE SAÚDE C)

Educação em saúde é orientar as pessoas em geral a evitar doenças, que seria através de orientações diretas médico-paciente, através de campanhas. O objetivo principal é orientar a população a prevenir doenças, seja diabetes, hipertensão, viroses, diarréias, orientar para prevenir, a pretensão é fazer essa parte primária da atenção, prevenir 
doenças, porque

controla mais fácil as

doenças. Prevenção é

essa parte primaria da

saúde, evitar gastos e

prevenir as doenças.

(PROFISSIONAL

\section{DE SAUDE F)}

\section{CATEGORIA 3 - O papel do profissional é} reduzido a transmissor de informações

Discute acerca do papel e o envolvimento de cada profissional na execução das atividades educativas na ESF, demonstrando assim como estes profissionais se encarregam da prática de educar no campo da saúde.

Faz-se importante discutir questões relativas ao papel profissional frente às ações de educação em saúde, visto que cada categoria abordada desde médicos, odontólogos e enfermeiros, enquanto integrantes da ESF devem incluir em suas condutas o papel de educador em potencial, isso porque na saúde há uma necessidade crescente de se fomentar a educação como instrumento capaz de gerar autonomia aos usuários, de tornarem os mesmos cidadãos conscientes e emancipados.

[...] A parte de informações com a comunidade fica a cargo dos auxiliares de enfermagem, dos enfermeiros, a gente procura dar informações na medida em que a gente convive com os pacientes no hospital, mas essa parte geral fica com a enfermagem.

(PROFISSIONAL DE SAÚDE F)

Meu papel é mais orientações dentro do consultório, e a gente também discute as maneiras de fazer as campanhas de virose, de diabetes nessa parte geral, mas eu nunca participei diretamente de reuniões de grupo.

\section{(PROFISSIONAL}

\section{DE SAÚDE F)}

$\mathrm{Na}$ verdade não há o compromisso com a prática educativa que busque a formação da consciência de saúde enquanto direito de cidadania. Apesar dos profissionais enfatizarem $\mathrm{o}$ trabalho em equipe em momentos individuais e/ou coletivos, apenas se fala em orientações gerais, com enfoque no cuidado preventivo, pautado somente no repasse de informações pré-estabelecidas. 
Apresenta a dinâmica de atuação das

Eu atuo tanto na parte preventiva como curativa, por exemplo, a parte minha que eu desenvolvo a parte preventiva é a questão da realização de palestras sobre a saúde bucal, como deve ser feita a higiene oral, como é que desde a criança até o adulto, porque como se diz a saúde começa pela boca. Para realizar essas atividades quem se encarrega é uma equipe desde o auxiliar de consultório, como também o enfermeiro o psicólogo, o dentista, quem realiza a palestra é um conjunto com o grupo da ESF.

(PROFISSIONAL DE SAÚDE G)

CATEGORIA 4 - As atividades de Educação em Saúde são baseadas numa ação pedagógica tradicional
ESF na realização das atividades educativas dirigidas ao publico, sendo abordadas questões como planejamento que envolve a escolha dos temas e espaços, além das metodologias e por fim a avaliação das ações executadas.

(...) orientações no geral, no dia a dia, são no meu consultório. E em coletivo levo a equipe para o auditório através de palestras na própria unidade.

(PROFISSIONAL DE SAÚDE A)

$\mathrm{Eu}$ trabalho bastante com os hipertensos, e diabéticos na unidade de saúde, no CRAS e escolas.

\section{(PROFISSIONAL DE SAÚDE B)}

Atualmente é mais no consultório, durante as consultas.

esporadicamente nas visitas as zonas rurais. Minha demanda é pouca então as 
consultas dão para ser

bem exploradas.

(PROFISSIONAL

DE SAÚDE D)

Quanto ao planejamento que envolve a escolha de temas e avaliação das atividades educativas foi observado durante o processo de análise que os discursos ficaram divididos, há profissionais de saúde que reforçam a visão descontextualizada da realidade ao qual está inserido, o que será discutido mais adiante. E outros verbalizaram haver inicialmente um planejamento com base nas necessidades observadas, tanto em consultas na UBS, assim como, os sugeridos por outros, como professores das escolas a partir da detecção de necessidade dos alunos.

Com certeza há um planejamento, dependendo do grupo, se for adolescente a gente vai focar a parte da sexualidade, o caso das drogas, e as gestantes a parte do pré-natal, os cuidados com a criança pósparto, durante o prénatal, o idoso a questão da medicação se estão tomando nas horas certas.
(PROFISSIONAL DE SAÚDE A)

De acordo com a identificação das necessidades, que são visualizadas nas consultas.

\section{(PROFISSIONAL} DE SAÚDE B)

É perceptível o compromisso de buscar uma integração entre ação educativa $x$ perfil epidemiológico, o que favorece o processo de ensino aprendizagem, pois para realizar uma educação em saúde comprometida com o dever social de cidadania se faz necessário buscar o saber pré-existente do individuo, não desconsiderando esse fator e sim partindo dele e o reconstruindo de forma a garantir a contribuição mútua na construção do saber popular.

Porém, ainda foi identificada a presença de uma conduta retrógrada que se reproduz no discurso dos profissionais, pois eles dizem seguir o que é preconizado pelo Ministério da Saúde sem vincular a realidade local, seguindo apenas os folhetos, manuais e cronogramas. Esse caráter é notório nas falas seguintes:

É de acordo com o preconizado pelo 
Ministério e o que esta

ao meu alcance.

(PROFISSIONAL

DE SAÚDE D)

Quando a gente vai desenvolver essas atividades a gente deixa bem aberto assim principalmente pra o público participar, "a gente enfoca mais a parte das doenças orais, a questão da carie, das doenças periodontais, a gente segue um cronograma que agente realiza em equipe", mas deixa bem aberto pra população fazer pergunta e gerar uma discussão em grupo.

(PROFISSIONAL DE SAÚDE G) intuito de garantir a melhoria do serviço, bem como, garantir o reconhecimento do que foi positivo e/ou negativo, esta não existe pelo menos por parte dos participantes do estudo, há sim, uma auto-avaliação. Os profissionais entrevistados afirmam reconhecer quando a atividade é produtiva:

A avaliação é feita pelos resultados obtidos, o índice de caries é menor após as atividades educativas, a escovação é melhor. A população é ativa perguntam.

\section{(PROFISSIONAL} DE SAÚDE H)

Os demais profissionais também afirmam haver auto-avaliação. Eles refletem se realmente houve interação entre profissional-usuário, se a adesão foi boa o suficiente, se realmente houve interesse participativo, o que ao final funciona como uma avaliação para eles; como é explicito nos discursos:

Vale ressaltar que os profissionais médicos não responderam essas perguntas já que afirmaram não realizarem educação em saúde para as coletividades e de forma planejada.

Com relação às avaliações que deveriam existir ao fim das atividades, no

A avaliação é feita pela adesão, se há uma boa aceitação é avaliado positivamente, na maioria das vezes eles 
participam

ativamente.

(PROFISSIONAL

DE SAÚDE B)

Existe avaliação. O

pessoal não tem

vergonha não, eles

interagem, alguns

interagem, outros a

gente tem que

direcionar as

perguntas. Não tem

aquele medo não, a

gente já conhece o

público, há um

momento só para

perguntas, eles vão se

soltando durante a

atividade.

(PROFISSIONAL

DE SAÚDE C)

A gente faz uma análise entre a gente e ver se conseguimos alcançar atingir o que queríamos repassar para a população e a gente avalia o interesse da população pelo tema.

(PROFISSIONAL DE SAÚDE G)
Há aqueles que não referem haver

qualquer tipo de avaliação ao fim das ações desenvolvidas como é explícito pelos profissionais a seguir:

Ao fim dessas atividades não existe auto-avaliação, ali a gente faz aquela palestra se eles têm alguma dúvida, aí se tiver na hora, se não tiver. Alguns tiram muitas dúvidas, outros ficam calados

\section{(PROFISSIONAL} DE SAÚDE A)

Não há avaliação nem por parte dos usuários nem mesmo profissional.

(PROFISSIONAL DE SAÚDE D)

\section{CATEGORIA 5 - A educação popular tem} o modelo de cuidado biomédico como principal obstáculo para a efetividade das ações educativas

Apresenta os principais obstáculos apresentados pelos profissionais para a execução das atividades educativas. 
O conjunto das falas permitiu perceber que poucos profissionais possuem condições razoáveis para atuar e realizar práticas educativas inovadoras:

Obstáculo mesmo não tem muito, porque sempre que a gente quer realizar para nós é fornecido o transporte, material, existe material, como entrega de kits de escova, creme dental, isso tem disponível, a gente utiliza $\mathrm{o}$ material fornecido pelo governo federal, temos os kits do PSE, com os dentes.

\section{(PROFISSIONAL}

DE SAÚDE G)

Não há obstáculos, quando há disposição de materiais para realizar as atividades a gente realiza, às vezes de três em três meses, às vezes de seis em seis meses. A adesão é fantástica, se você vai para escola você encontra 0 maior número de pessoas que possa participar. No consultório a gente realiza as orientações individualmente.

\section{(PROFISSIONAL}

\section{DE SAÚDE H)}

A maioria revela não considerarem boas as condições oferecidas pelo município, em especial, pela falta de investimento da gestão, devido à desvalorização na mediação educativa, papel profissional que possibilita a efetivação da cidadania dos indivíduos.

Ineficiência da equipe, não há um trabalho continuado, eu tento planejar uma ação, mas infelizmente não há apoio da secretaria de saúde, em especial dos gestores, como no caso do projeto de visita domiciliar e entrega da medicação de hipertensos e diabéticos, não houve avanço exatamente pela falta de apoio no fornecimento das medicações, que eles preferem entregar na farmácia básica, a 
adesão da população é

até boa, em especial

os idosos, porém, já os

adolescentes têm certa

resistência.

(PROFISSIONAL

DE SAÚDE B)

Outro impasse referido para questão da metodologia, o município não disponibiliza condições para tal, tornando a atividade tradicional e restrita o que sem dúvida reflete nos resultados a alcançar.

Às vezes, assim, a questão de querer organizar uma coisa mais atrativa, que chame atenção, a questão financeira a gente tem dificuldade para preparar material, muitas vezes a gente não dispõe de transporte para a gente atender a outros locais carentes como a zona rural, às vezes ate mesmo o data show que não tem na saúde a gente tem que pedir na secretaria de educação emprestado. Aí essas coisas dificultam um pouco, mas a gente não deixa de realizar com outras coisas, como cartaz, álbum seriado, ou muitas vezes vai pegar emprestado para executar essas atividades. Há uma boa aceitação, esse não é um obstáculo, eles ficam satisfeitos a gente vê a interação, perguntam, faz relatos pessoais dependendo do tema, então a gente ver que tem uma aceitação boa.

\section{(PROFISSIONAL} DE SÁUDE C)

Os profissionais colocam o modelo hegemônico clínico da saúde como desafio a se superar, visto que a população só busca o serviço de saúde quando é acometido por uma doença, deixando a desejar na prevenção. Os discursos seguintes demonstram essa insatisfação.

A dificuldade que tem é unir todos, a agente de saúde tem que unirem todos aí é um trabalho, você sabe 
que o povo é

trabalhoso, unir, aceitar, reconhecer a importância é o lado trabalhoso da gente.

(PROFISSIONAL DE SAÚDE A)

A grande demanda e a própria estrutura da saúde que não possibilita outra coisa pra gente fazer, além disso, (as consultas). A medicina tem sido muito uma coisa que não deveria ser curativa, ao meu ponto de vista, a formação da medicina deve ser preventiva, mas a realidade é essa, pelo menos daqui da região. A maioria da população busca a medicalização, não deveria ser assim, mas a grande maioria logo procura o que você tá passando.

(PROFISSIONAL DE SAÚDE E)
CATEGORIA 6 - A integralidade se mostra como um desafio na realidade das práticas educativas

Apresenta a opinião dos profissionais sobre a efetivação da integralidade no cuidado em saúde realizado pela ESF, nesta categoria os profissionais apresentam seus julgamentos com base na realidade que vivenciam, expondo se a integralidade é alcançada ou não em suas práticas.

O termo integralidade assume uma ampla variedade de significados, sendo inclusive pouco esclarecido entre muitos profissionais o seu verdadeiro sentido. Para Mattos (2005, p. 5) integralidade é "uma recusa por parte dos que se engajam na formulação de uma política em reduzir o objeto de suas políticas, ou melhor, de reduzir a objetos descontextualizados os sujeitos sobre os quais as políticas incidem”.

Em algumas falas percebemos claramente as principais dificuldades que se apresentam para efetivar o cuidado integral:

A saúde seria mais abrangente se funcionasse esse seria o conceito ideal, mas o que o SUS propõe, ele é um dos melhores modelos de saúde do mundo, o problema é que não consegue se efetivar, não consegue 
atender

uma

população tão grande, então fica difícil. Pelo

CRM o médico era para atender 16 pessoas por dia, o que não se aplica geralmente você tem que consultar 100 pessoas e não dá pra fazer isso com qualidade.

(PROFISSIONAL DE SAÚdE E)

Para outros o termo integralidade se reduz a um fator único, no caso relatado a saúde bucal o que revela uma noção limitada e restrita:

[...] ainda há carência em relação a isso, mas a gente tenta com o dia a dia melhorar e ver também a questão, não é tudo $100 \%$ mas a gente procura buscar o melhor para trazer a melhoria principalmente da saúde bucal da nossa população.

(PROFISSIONAL DE SAÚDE G).

\section{DISCUSSÃO}

De acordo com a realidade em estudo foram detectados desafios e pontos importantes que merecem serem discutidos e repensados pelas equipes da ESF e pela gestão de saúde do município na finalidade de promover modificações no cuidado de saúde, podendo assim torná-lo mais comprometido com a integralidade, e com a proposta inovadora da educação em saúde.

Os problemas visualizados foram a compreensão da Educação em Saúde de forma tradicional e reducionista, enfatizando a verticalização das informações repassadas pelo profissional para a comunidade ou indivíduo, de modo que o papel do profissional de saúde fica restrito somente a transmissão de conhecimentos previamente estabelecidos, sendo o mesmo considerado o detentor do conhecimento e o usuário um mero depósito de informações. Limitando-se ao modelo de saúde hegemônico biologicista, o qual influencia a prática profissional e a relação queixa-conduta, com condutas educativas autoritárias e pautadas apenas na prevenção das doenças.

A ausência do profissional médico na efetivação das atividades educativas, por estar atrelado ao estabelecimento de metas pontuais como, por exemplo, a realização de consultas. A inexistência de incentivo da gestão, por seguir as metas ministeriais, sem haver preocupação com as necessidades de saúde e valorização da autonomia da população. O 
forte apego ao tradicionalismo da ação pedagógica, com espaços, temas e metodologias pouco eficientes e atrativas. Inexistência de recursos materiais e de capacitação teórico-metodológica para os profissionais. Ineficiência do sistema de ensino e da formação profissional que não investe em um conhecimento capaz de inovar metodologicamente e de garantir uma ação pedagógica transformadora.

Diante desses empecilhos, se faz importante discutir a prática da educação em saúde nas ESF. Haja visto que avanços tenham acontecido, entretanto pouco tem se aplicado na realidade dos serviços, pois a maioria dos profissionais não é capacitada para lidarem com o papel de educadores em saúde (PEREIRA, 2003).

Nessa perspectiva, visando à qualidade do cuidado de saúde é primordial investir na formação dos profissionais. Inclusive as universidades devem inserir em seus currículos inovações metodológicas, e condutas menos tradicionais de modo que os graduandos se familiarizem com abordagens pedagógicas diferenciadas ao público, e que permitam uma participação mais ativa dos usuários de saúde, a fim de que eles estejam inseridos desde o planejamento das ações bem como na sua execução não de forma indireta, mas expondo suas experiências e trocando conhecimentos numa configuração que seja abolida a verticalização do saber. (ROSA;
MAFFACCIOLLI; NAUDERER; PEDRO, 2006).

A prática rotineira e efetiva de educação permanente para os profissionais atuantes no serviço, possibilita uma aproximação com o público, e assim aprender a lidar com as problemáticas que surgem é preciso estar reaprendendo, pois há uma grande dinamicidade no processo ensinoaprendizagem, dessa forma é preciso praticar novas idéias, por mais que a metodologia não seja uma fórmula pronta, mas ela pode ser recriada, reinventada e sem dúvida possibilitar experiências positivas no campo educacional. (ROSA, 2011).

As parcerias que devem ser estimuladas por parte da gestão, com a sociedade e o serviço de saúde, através do planejamento conjunto, entre os diversos setores da sociedade: o comércio; as instituições sociais, como abrigos, creches e escolas; que podem contribuir de forma que todos sejam beneficiados.

Infere-se a necessidade de maior empenho e compromisso da gestão em garantir condições a ESF e incentivo aos profissionais, que visa construir uma nova consciência na sociedade, é preciso acreditar na prevenção das doenças e em condutas de vida saudáveis, não de forma autoritária, mas dentro dos padrões de cada realidade, obedecendo às necessidades de saúde de cada grupo homogêneo. 
As pessoas precisam se identificar como cidadãos que conhecem seus direitos e lutam por eles, devem inverter seus valores abandonando a passividade no sistema e assumindo uma postura mais ativa diante do cuidado de si, através da conscientização, da construção crítica do conhecimento, tornandose sujeitos com autonomia (FREIRE, 1996).

Para promover um cuidado de saúde integral e, que realmente alcance resultados produtivos, é fundamental a existência de uma política de educação em saúde sólida que fortaleça o trabalho da ESF, garantindo incentivo de formação permanente dos profissionais. Enquanto a educação em saúde continuar sendo tratada como apenas uma ação pontual nos serviços de saúde, essa realidade não será mudada, é preciso haver investimentos e fiscalização dos recursos destinados a educação em saúde.

\section{CONCLUSÕES}

O estudo demonstrou que a educação em saúde realizada segue uma dinâmica da prática pedagógica tradicionalista, demarcada por influências do modelo de saúde médico hegemônico, no qual a prevenção e as práticas higienistas autoritárias baseadas na culpabilização dos sujeitos e transmissão vertical das informações são o foco das ações em saúde.

A educação em saúde na ESF do município não efetiva a integralidade, visto que a população não é compreendida em sua complexidade, não há consideração dos aspectos determinantes no processo saúdedoença. Cabe a ESF rever condutas tradicionais de verticalização do saber, é necessário reconhecer o papel e o valor do cidadão e principalmente a construção mútua do saber. Romper com o modelo hegemônico de saúde uma das possibilidades é através da educação em saúde, usada de forma inteligente, valorizando o diálogo e garantindo a autonomia dos sujeitos bem como sua criticidade, temos o dever social de instaurar o desejo de mudança e a tomada de atitude, a começar pela saúde e educação.

\section{REFERENCIAS}

\section{ALVES, V. S. Um modelo de educação em saúde para o Programa Saúde da Família: pela integralidade da atenção e reorientação do modelo assistencial,} Interface - Comunic., Saúde, Educ., v.9, n.16, set.2004/fev.2005, p.39-52.

CARVALHO, S. R.; CUNHA, G. T. A Gestão da atenção na saúde: Elementos para se pensar a mudança da organização na saúde. In:CAMPOS, G.W. de S. et al. (org.). Tratado de saúde coletiva. São Paulo: Hucitec; Rio de Janeiro: Ed. Fiocruz, 2006. 837-868

CASTRO, A. SUS: Ressignificando a promoção da saúde. (Saúde em debate; v.175). São Paulo: Hucitec: opas, 2006. 222p.

COELHO, M. T. D. A. ALMEIDA FILHO, N. Análise do Conceito de Saúde a partir da Epistemologia de Canghilhem e Foucalt. In. Goldenberg P; Marsiglia RMG; Gomes MHA. (Orgs.) O Clássico e o Novo: 
Tendências, objetos e abordagem em ciências sociais e saúde. Rio de Janeiro: HUCITEC; 2003. p. 101-13.

IBGE. Instituto Brasileiro de Geografia e Estatística. Brasil município por município. Ministério da Saúde. Disponível em: http://www.ibge.gov.br/cidadesat/topwindow. htm?1. Acesso em: 10 de julho de 2011.

PEREIRA, A. L. F. As tendências pedagógicas e a prática educativa nas ciências da saúde. Cad. Saúde publica Rio de Janeiro, 2003. set-out, 19(5): 1527-1534.

ROSA, E. M. Educação popular, integralidade e formação em enfermagem no cenário da extensão universitária. Dissertação (Mestrado) - Universidade Federal do Rio Grande do Sul, Escola de Enfermagem, Programa de pós graduação em Enfermagem, Porto Alegre, BR-RS, 2011.119f.

ROSA, R. B; MAFFACCIOLLI, R.; NAUDERER, T. M; PEDRO, E. N. R. A educação em saúde no currículo de um curso de enfermagem: $O$ aprender para educar. Rev Gaucha de Enferm, Porto Alegre (RS) 2006 jun; 27(2): 185-92.

STOTZ, E. N. Os Desafios para o SUS e a Educação Popular: uma Análise Baseada na Dialética da Satisfação das Necessidades de Saúde. Escola Nacional de Saúde Pública, Projeto VER-SUS/Brasil | Departamento de Gestão da Educação na Saúde/SGTES/MS. Caderno de Textos Série B. Textos Básicos. MINISTÉRIO DA SAÚDE. Brasília - DF 2004 (p.285 a 301)

VASCONCELOS, C. M.; PASCHE, D. F. O Sistema Único de Saúde. In: CAMPOS, G.W. de $\mathrm{S}$. et al. (org.). Tratado de saúde coletiva. São Paulo: Hucitec; Rio de Janeiro: Ed. Fiocruz, 2006. 531-562p.

VASCONCELOS, E. M. Educação popular: de uma prática alternativa a uma estratégia de gestão participativa das políticas de saúde. PHYSIS: Ver. Saúde Coletiva, Rio de janeiro, 2004.14(1): 67-83. 